\title{
Assessing time-correlativity of the Late Miocene-Early Pliocene Biogenic Bloom across multiple divergence regions using bulk sediment carbon and oxygen isotopes
}

\author{
D. JANA ${ }^{1 *}$ AND G. R. DICKENS ${ }^{1}$
}

${ }^{1}$ Department of Earth, Environmental and Planetary Sciences, Rice University, Houston, TX 77005

(*correspondence: dj20@rice.edu)

The Late Miocene-Early Pliocene Biogenic Bloom describes the phenomenon whereby, between approximately 8 and 4.3 Ma, biogenic accumulation on the seafloor (and presumbaly primary productivity in surface waters) increased 2-4 times at divergence zones of the Indian and Pacific Oceans [1]. High-resolution stable isotope records from multiple Eastern Equatorial Pacific (EEP) sites demonstrate remarkable high amplitude, short frequency time-correlative variations across the Biogenic Bloom [2]. At issue is whether such variability occurs in other regions.

Here we report high-resolution bulk stable carbon and oxygen isotopic ratios of deep marine sediment samples obtained from DSDP Site 590 located on Lord Howe Rise and beneath the Tasman Front north-east of New Zealand. This information is placed on a common biostratigraphic framework [3], alongside data from IODP Sites U1338 and 573 from the EEP [2]. Preliminary results indicate that longterm trends and short-term variations in stable isotope records from the southwest Pacific and the EEP can be tied together. We suggest the Biogenic Bloom was a complex phenomenon that, in detail, involved rapid changes in ocean circulation and nutrient delivery across multiple sites throughout the Indian and Pacific oceans.

[1] Dickens \& Owen (1999) Marine Geology, 161.1, 75-91. [2]Reghellin et al. (2015) Paleoceanography 30.10, 12611286. [3] Gradstein et al. (2012) eds. The geologic time scale, Elsevier. 